63 卷 608 号 $(1997-4)$

\title{
アクティブノイズ制御系への二自由度制御手法の適用*
}

\author{
中 井 英 雄*1, 天野 也寸志*1 \\ 木 村 忠 司*2, 長 野 誠*2
}

\section{Two-Degree-of-Freedom Control Approach to Active Noise Control}

\author{
Hideo NAKAI, Yasushi AMANO, \\ Tadashi KIMURA and Makoto NAGANO
}

\begin{abstract}
Most of the studies on active noise control systems have used an open-loop feed-forward (FF) control system for the past several years. The FF control system requires a reference signal of a noise. Unless the reference signal has good coherence with a noise, the FF control system cannot achieve good control performance. In such a case, however, the closed-loop FB control system requiring no reference signal is effective. Although the key factor of the closed-loop control system is stability, the conventional adaptive algorithm cannot always assure the stability for systems the characteristics of which change. In fact several studies have been done on the FB control system in the last few years. However, little attention has been given to the robust stability. In this study we proposes a 2-degree-of-freedom (2DF) control system consisting of a FF compensator and a robust $\mathrm{FB}$ compensator. The FF compensator is designed using the conventional Filtered-X LMS algorithm and the robust $\mathrm{FB}$ compensator is designed using a new adaptive algorithm that is based on the LMS method. The advantage of this new algorithm is that it ensures the robust stability of a closed loop by adjusting the step size that corrects the weight of a FIR adaptive filter. This study confirms the validity of this $2 \mathrm{DF}$ control system by applying it to an experimental system that cannot be controlled well with the conventional FF control system.
\end{abstract}

Key Words : Noise Control, Adaptive Control, Noise, Stability, Sound, FIR Filter, Robust

\section{1.はじめに}

騒音のアクティブ制御(Active Noise Control : $\mathrm{ANC})$ とは, 騒音と同振幅・逆位相の音をスピーカで 人工的に作り，この音を用いて騒音を低隇する技術で あり(1), 多くの場合適応ディジタルフィルタを用いた フィードフォワード $(\mathrm{FF})$ 制御方式で構成されてい る(2) (4). FF 制御方式の ANCでは, 騒音とそのリフ アレンス信号のコヒーレンスの良し悪しに騒音低減量 が大きく依存する.自動車車室内のエンジンこもり音 のように騒音とコヒーレンスがよいリファレンス信号 が得られる場合は，騒音を大きく低隇ができる(5)。一 方、騒音のリファレンス信号を用いないフィードバッ ク $(\mathrm{FB})$ 制御方式も研究されているが, 負㷌還路にお ける位相遅れのため, 従来の FB 制御方式の ANC は, ヘッドホーンのようにマイクとスピーカを近接して配 置できるケースに限定されている(6) (8). したがって， リファレンス信号の取得が難しいロードノイズのよう な非周期騒音を $\mathrm{FB}$ 制御方式の ANCで低隇するため

\footnotetext{
* 原稿曼付 1996 年 4 月 15 H.

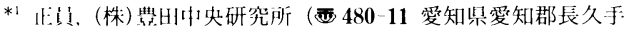
町店湫横道 411 )

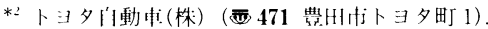

には，スピーカとマイクを近接して乗員の耳元に配置 する必要がある。しかしながら, 乗員の姿勢に応じて 耳位置が変化することや, 耳元のスピーカとマイクに より乗員が圧迫感を感じることなど, この方策は好ま しくない. しかし，スライディングルーフで発生する ウインドスロブ(Wind throb) ${ }^{(9)}$ のように周期性をも つ騒音を対象にすれば, 過去の信号を用いて制御する ことが可能である。そのため, 負帰還路の位相遅れに 制限されずに，つまりスピーカとマイクを近接させる ことなく, FB 制御方式を適用できる.

本研究では, 周期騷音を対象とし, マイクとスピー 力を近接して配置することなく自動車の車室内程度の 大きさの空間で騒音を低減できる FB 補償器を提案す る.この $\mathrm{FB}$ 補償器の特徴は, 適応ディジタルフィル タのフィルタ係数を更新するステップサイズパラメー 夕を調節することにより閉ループのロバスト安定性を 補償しかつ, 係数更新に不感帯を設けパラメータの収 束性を補償したことである。ささらに,この FB 補償器 と従来の filtered-X LMSアルゴリズム(10) に基づく 適応 FF 補償器とを組合せた二自由度 $(2 \mathrm{DF})$ 制御系 を提案する。この $2 \mathrm{DF}$ 制御系は, FB 補償器, もしく は FF 補償器の騒音低減効果よりも大きな騒音低減効 果を期待できる。このロバストな FB 補償器を用いた 
$\mathrm{ANC}$ と $2 \mathrm{DF}$ 制御系の騒音低減効果を実験により検 証する.

\section{おもな記 号}

$C_{1}\left(z^{-1}, k\right): k$ 時刻の適応 $\mathrm{FF}$ 補償器 (タップ数 $N 1$ の FIR フィルタ)

$$
C_{1}\left(z^{-1}, k\right)=\sum_{i=0}^{N 1-1} C_{1}^{2}(k) z^{-i}
$$

$C_{2}\left(z^{-1}, k\right): k$ 時刻の適応 $\mathrm{FB}$ 補償器 (タップ数 $N 2$ の FIR フィルタ)

$C_{2}\left(z^{-1}, k\right)=\sum_{i=0}^{N 2-1} C_{2}^{i}(k) z^{-i}$

$D$ ：制御対象とモデルの誤差の上限

$E\left(z^{-1}\right)$ : Control Source と Observer 間の特性 $G\left(z^{-1}\right)$ の同定モデル(タップ数 $M$ の FIR フ イルタ)

$E\left(z^{-1}, k\right)=\sum_{i=0}^{M-1} E^{\prime}(k) z^{-i}$

$F(k): k$ 時刻のフィードバックコントローラのフィ ル夕係数の絶対值の和

$G\left(z^{-1}\right)$ : Control Source と Observer 間の特性 $G_{r}\left(z^{-1}\right)$ : Noise Source と Observer 間の特性 $d(k)$ : リファレンス信号に加わる観測ノイズ信号

$\epsilon(k)$ : 拡張詋差信号

$l(k)$ : リファレンス信号に表れないノイズ信号

$n(k)$ : リファレンス信号に表れるノイズ信号

$p(k)$ : 制御信号

$q(k) \quad$ : リファレンス信号 $q(k)=n(k)+d(k)$

$r(k)$ : ノイズ信号

$u(k)$ : フィードバック制御系の制御信号

$v(k)$ : フィードフォワード制御系の制御信号

$w(k)$ : Observer で観測されるノイズ信号

$x(k): \mathrm{FB}$ 制御器への入力

$y(k)$ : Observer で観測される誤差信号

$z^{-1}$ : 遅延演算子, または $z$ 演算子

$\Delta\left(z^{-1}\right):$ 制御対象と同定モデルの誤差

$\alpha_{2}(k)$ : フィードバック制御系のフィルタ係数調整重 み

$\|x(k)\|_{\infty}:\|x(k)\|_{\infty}=\max _{0 \leq i \leq k}|x(k-i)|$ で定義されるノル 么

\section{2. 制御アルゴリズムの導出}

2・1 Robust Filterd-X LMS アルゴリズム ま ず, 図 1 のブロック図に示す適応フィードバック制御 系の構成を行う.

図中に示す $\mathrm{FB}$ 補償器 $C_{2}\left(z^{-1}, k\right)$ のフィル夕係数

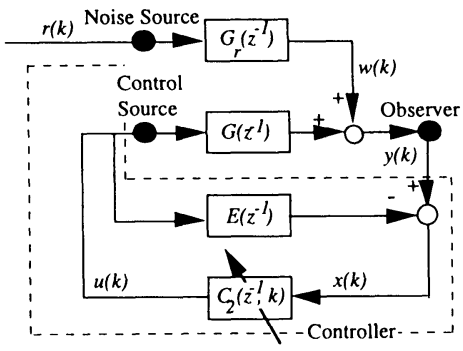

Fig. 1 FB adaptive noise control system block diagram

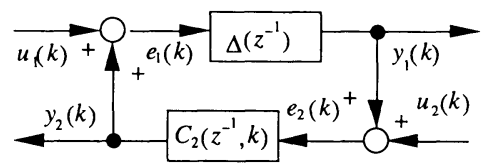

Fig. 2 Closed loop block diagram

は, 閉ループが安定かつ, 誤差信号が小さくなるよう に調整されなければならない。そこで，そのような条 件を満たすパラメータ調整アルゴリズム(以下では, Robust Filtered-X（RFX)アルゴリズムと記す)の構 成方法を述べる。ただし，以下のアルゴリズム中で用 いるモデル $E\left(z^{-1}\right)$ のフィルタ係数は制御を行う前に, あらかじめ同定されているとする。

RFX アルゴリズムを提示する準備として,フィー ドバック制御系の閉ループの安定条件とフィルタ係数 の収束条件を示す。まず, 適応フィードバック系の閉 ループの安定条件を示すために, 有界な外部入力 $u_{1}(k), u_{2}(k)$ をもつ図 2 のシステムを設定する.

定理 1 閉ループの安定条件

図 2 のシステムにおいて, $C_{2}\left(z^{-1}, k\right), \Delta\left(z^{-1}\right)$ はそ れぞれ式(1)，（2）を満たす安定なフィル夕である.

$$
\begin{aligned}
& C_{2}\left(z^{-1}, k\right)=\sum_{i=0}^{N 2-1} C_{2}^{z}(k) z^{-i} \\
& \left\|\Delta\left(z^{-1}\right) e_{1}(k)\right\|_{\infty} \leq D\left\|e_{1}(k)\right\|_{\infty}, 0<D<\infty
\end{aligned}
$$

このとき,図 2 の閉ループ系は式 $(3)$ が成り立つとき 安定である.

$$
F(k) D<1
$$

ただし， $F(k)$ は式(4)で与えられる.

$$
F(k)=\sum_{i=0}^{N 2-1}\left|C_{2}^{i}(k)\right|
$$

証明

ここで, 式(2), (4)より, $y_{1}(k), y_{2}(k)$ は, 以下の ように書き換えられる。

$$
\left|y_{1}(k)\right| \leq\left\|y_{1}(k)\right\|_{\infty}=\left\|D\left(z^{-1}\right) e_{1}(k)\right\|_{\infty}
$$


$\leq D\left\|e_{1}(k)\right\|_{\infty} \leq D\left\|u_{1}(k)\right\|_{\infty}+D\left\|y_{2}(k)\right\|_{\infty}$

$$
\begin{aligned}
& \left|y_{2}(k)\right|=\left|\sum_{i=0}^{N 2-1} C_{2}^{i}(k) e_{2}(k-i)\right| \\
& \leq \sum_{i=0}^{N 2-1}\left|C_{2}^{2}(k)\right| \max _{0 \leq i \leq N 2-1}\left|e_{2}(k-i)\right| \\
& \leq F(k)\left\{\max _{0 \leq i \leq N 2-1}\left|y_{1}(k-i)\right|\right. \\
& \left.\quad+\max _{0 \leq i \leq N 2-1}\left|u_{2}(k-i)\right|\right\} \quad \ldots \ldots \ldots \ldots . . .
\end{aligned}
$$

ここで, 式 (6)に式 ( 5 )を代入すると次式となる. $\left|y_{2}(k)\right| \leq F(k) D\left\|u_{1}(k)\right\|_{\infty}+F(k) D\left\|y_{2}(k)\right\|_{\infty}$

$$
+F(k) \max _{0 \leq i \leq N 2-1}\left|u_{2}(k-i)\right|
$$

仮定より, $u_{1}(k), u_{2}(k), F(k)$ は有界だから,

$$
F(k) D\left\|u_{1}(k)\right\|_{\infty}+F(k) \max _{0 \leq i \leq N 2-1}\left|u_{2}(k-i)\right| \leq \gamma
$$

となる $\gamma$ が存在する.ここで, 式 ( 3 )より,

$$
F(k) D \leq \alpha<1
$$

となる $\alpha$ が存在する。この $\alpha, \gamma$ を用いると, 式(7) は次式となる.

$$
\left|y_{2}(k)\right| \leq \alpha\left\|y_{2}(k)\right\|_{\infty}+\gamma
$$

ここで, $y_{2}(k)$ が有界でないと仮定すると, 次式を 満たすような点列 $\left\{k_{d}^{j}\right\}$ が存在する.

(1) $\left|y_{2}\left(k_{d}^{j}\right)\right| \geq\left|y_{2}(l)\right| \quad\left(0 \leq l \leq k_{d}^{j}\right)$

(2) $\lim _{j \rightarrow \infty}\left|y_{2}\left(k_{d}^{j}\right)\right|=\infty$

この任意の $\left\{k_{d}^{j}\right\} に$ 対し, 式(10)およびノルムの定義よ り次式が成り立つ。

$$
\left|y_{2}\left(k_{d}^{j}\right)\right| \leq \alpha\left|y_{2}\left(k_{d}^{j}\right)\right|+\gamma
$$

したがって, $\left|y_{2}\left(k_{d}^{j}\right)\right| \leq \gamma(1-\alpha)^{-1}$ が成り立ち, $y_{2}\left(k_{d}^{j}\right)$ は有界となり仮定に矛盾する。したがって, $y_{2}(k)$ は すべての $k$ で有界である。 また, $u_{1}(k), y_{2}(k)$ が有界 だから, 式(5)より， $y_{1}(k)$ も明らかに有界である.

以上より， $y_{1}(k), y_{2}(k)$ が有界だから閉ループは安 定である.

(証明終わり)

図 1 において $\Delta\left(z^{-1}\right)=G\left(z^{-1}\right)-E\left(z^{-1}\right)$ と定義すれ ば, 図 1 の安定性に対して定理 1 を適用できる.

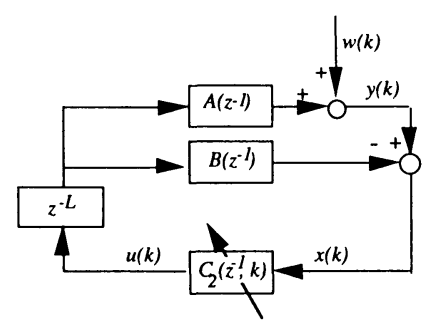

Fig. 3 The closed loop of the FB adaptive noise control system
次に，図1において制御目的を達成するための $C_{2}\left(z^{-1}, k\right)$ のフィル夕係数 $C_{2}^{i}(k)$ の調整方法について 述べる.まず証明を行うため, 図 1 のシステムを以下 のように書き換える。サンプリング周期を TS とし， $C_{2}\left(z^{-1}, k\right)$ の演算によるむだ時間を含めて, $G\left(z^{-1}\right)$, $E\left(z^{-1}\right)$ のむだ時間を $T s L$ とする.さらに, $G\left(z^{-1}\right)$, $E\left(z^{-1}\right)$ からむだ時間を除いた伝達関数を, それぞれ $A\left(z^{-1}\right), B\left(z^{-1}\right)$ として次式で定義する.

$$
\begin{aligned}
& A\left(z^{-1}\right)=G\left(z^{-1}\right) z^{L} \\
& B\left(z^{-1}\right)=E\left(z^{-1}\right) z^{L}
\end{aligned}
$$

ここで定義した関数を用いると図 1 の閉ループは図 3 のように書き直すことができる.

ここで,閉ループにむだ時間がなく, $A\left(z^{-1}\right)=$ $B\left(z^{-1}\right)$ である理想的な系を想定すると, $\mathrm{FB}$ 補償器が $C_{2}\left(z^{-1}, k\right)=-B^{-1}\left(z^{-1}\right)$ のとき, 誤差信号 $y(k)$ が零と なる.ここでは, $B^{-1}\left(z^{-1}\right)$ をタップ数 $N 2$ の FIR フ イルタで記述できる程度にタップ数 $N 2$ は十分に大き いとする.

定理 2 フィルタ係数の収束条件

十分大きな $N 2$ をもつ $C_{2}\left(z^{-1}, k\right)$ に対して, フィル 夕係数調整則

$$
\begin{aligned}
& C_{2}^{i}(k)=C_{2}^{i}(k-1)-\alpha_{2}(k) z(k-i) e(k) \\
& (i=0, \cdots, N 2-1) \\
& \alpha_{2}(k)>0 \\
& z(k)=\sum_{i=0}^{M-1} E^{i} x(k-i)
\end{aligned}
$$

を適用した場合, フィルタ係数が収束するための十分 条件は,

$$
|e(k)|<|x(k)-x(k-L)|
$$

のときに, フィル夕係数の更新を行わないことであ る.ただし, $e(k)$ は次式で与えられる拡張誤差 (augumented error)信号である.

$$
\begin{aligned}
& e(k)=y(k)+h(k) \\
& h(k)=-\left(B\left(z^{-1}\right) z^{-L} C_{2}\left(z^{-1}, k\right)\right. \\
& \left.\quad-C_{2}\left(z^{-1}, k\right) B\left(z^{-1}\right) z^{-L}\right) x(k)
\end{aligned}
$$

証明

図 3 に示す記号を用いると残差出力 $y(k)$ は, 以下 のように整理できる。

$$
\begin{gathered}
y(k)=G\left(z^{-1}\right) u(k)+w(k) \\
=A\left(z^{-1}\right) z^{-L} C_{2}\left(z^{-1}, k\right) x(k)+w(k) \\
=B\left(z^{-1}\right) z^{-L} C_{2}\left(z^{-1}, k\right) x(k)+\left(A\left(z^{-1}\right)\right. \\
\left.-B\left(z^{-1}\right)\right) z^{-L} C_{2}\left(z^{-1}, k\right) x(k)+w(k) \\
=B\left(z^{-1}\right) z^{-L} C_{2}\left(z^{-1}, k\right) x(k)+x(k) \\
\quad\left(\because x(k)=\left(A\left(z^{-1}\right)-B\left(z^{-1}\right)\right) z^{-L}\right. \\
\left.\quad \times C_{2}\left(z^{-1}, k\right) x(k)+w(k)\right) \\
=B\left(z^{-1}\right) z^{-L} C_{2}\left(z^{-1}, k\right) x(k)+B^{-1}\left(z^{-1}\right)
\end{gathered}
$$




$$
\begin{aligned}
& \times B\left(z^{-1}\right) x(k-L)-x(k-L)+x(k) \\
& =\left(B\left(z^{-1}\right) z^{-L} C_{2}\left(z^{-1}, k\right)-C_{2}\left(z^{-1}, k\right)\right. \\
& \left.\times B\left(z^{-1}\right) z^{-L}\right) x(k)+\left(C_{2}\left(z^{-1}, k\right)\right. \\
& \left.+B^{-1}\left(z^{-1}\right)\right) B\left(z^{-1}\right) x(k-L)+x(k)-x(k-L) \\
& =\left(C_{2}\left(z^{-1}, k\right)+B^{-1}\left(z^{-1}\right)\right) B\left(z^{-1}\right) x(k-L) \\
& +(x(k)-x(k-L))+\left(B\left(z^{-1}\right) z^{-L}\right. \\
& \left.\times C_{2}\left(z^{-1}, k\right)-C_{2}\left(z^{-1}, k\right) B\left(z^{-1}\right) z^{-L}\right) x(k)
\end{aligned}
$$

フィルタドリファレンス信号 $z(k)$ は, 式(13), (16) より式(21)のように表される.

$$
z(k)=B\left(z^{-1}\right) x(k-L)
$$

また, $N 2$ は十分に大きく, $B^{-1}\left(z^{-1}\right)$ をタップ数 $N 2$ の FIR フィルタで記述することが可能だから，

$B^{-1}\left(z^{-1}\right)=-B^{0} z^{0}-B^{1} z^{-1}-\cdots-B^{N 2-1} z^{-(N 2-1)}$

となる FIR フィル夕を定義することができる。

ここで，式(20)に，式(18)，(19)，(21)，(22）を適用 し, $B^{-1}\left(z^{-1}\right)$ の係数を推定する可調整パラメー夕を $P(k)$ とすると

$$
e(k)=\Delta P(k)^{T} Z(k)+x_{L}(k)
$$

を得る。ただし，

$$
\begin{aligned}
& x_{L}(k)=x(k)-x(k-L) \cdots \cdots \cdots \cdots \cdots \cdots \cdots \cdots \\
& Z(k)=(z(k), z(k-1), \cdots, z(k-(N 2-1)))^{T}
\end{aligned}
$$

$$
P^{*}=\left(B^{0}, B^{1}, \cdots, B^{N 2-1}\right)^{T}
$$

$P(k)=\left(C_{2}^{0}(k), C_{2}^{1}(k), \cdots, C_{2}^{N 2-1}(k)\right)^{T}$

$\Delta P(k)=P(k)-P^{*}$

である。このとき式(14)は，

$$
\Delta P(k)=\Delta P(k-1)-\alpha_{2}(k) Z(k) e(k) \cdot
$$

となる。

正定値関数 $V(k)$ を定義する.

$$
V(k)=\Delta P^{T}(k) \Delta P(k)
$$

この正定值関数の時間変化を示す関数 $\Delta V(k)$ は次式 で与えられる。

$$
\begin{aligned}
& \Delta V(k)=V(k)-V(k-1) \\
& \quad=(\Delta P(k)-\Delta P(k-1))^{T}(\Delta P(k)+\Delta P(k-1)) \\
& \quad=-\alpha_{2}^{2}(k) Z^{T}(k) Z(k) e^{2}(k) \\
& \quad-2 \alpha_{2}(k)\left(e(k)-x_{L}(k)\right) e(k) \cdots \cdots \cdots \cdots \cdots \cdot(31)
\end{aligned}
$$

リアプノフの安定論より, $-\Delta V(k)$ が準正定置関数 であればフィル夕係数 $P(k)$ は収束する. 式(31)より, - $\Delta V(k)$ が準正定值関数であるための十分条件は,

$$
|e(k)|<\left|x_{L}(k)\right| \text { のとき, } \alpha_{2}=0
$$

と求めることができる.

（証明終わり）

この定理は, 拡張誤差信号に対し不感帯を設け, 式 (17)の条件を満たすときに, フィル夕係数の更新を行 わないことと等価である。この定理により, $P(k)$ が
収束すれば $h(k)=0$ となり, $e(k)=y(k)$ となる.し

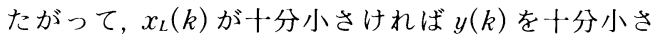
くでき制御目標を達成できる。ここで、制御帯域より も閉ループのもっているむだ時間が十分に小さく，こ のむだ時間に対して高周波の成分が十分小さい場合や ローパスフィルタなどで十分に除去できれば, $x_{L}(k)$ $\fallingdotseq 0$ とみなせる. すなわち, 式(17)の条件は以下に示 す RFX アルゴリズムから除くことも可能である.

以上から, モデル化誤差 $\Delta\left(z^{-1}\right)=G\left(z^{-1}\right)-E\left(z^{-1}\right)$ と適応 $\mathrm{FB}$ 補償器 $C_{2}\left(z^{-1}, k\right)$ が定理 10 条件を満たせ ば, 図 1 の閉ループ系は安定であり,かつ, $x_{L}(k)$ が十 分小さければ制御目的を達成できる。ただし, 制御目 的を達成するフィル夕係数 $C_{2}^{i}(k)$ の集合を $P_{1}$ とし， 定理 1 の条件を満たすフィル夕係数 $C_{2}^{i}(k)$ の集合を $P_{2}$ とした場合, $P_{1} \supset P_{2}$ でなければならない.

上述の定理 1,2 に基づく閉ループのロバスト安定 性抢よびフィル夕係数の収束性を補償する RFXアル ゴリズムは以下のように記述できる。

(RFX アルゴリズム)

step 1: $|e(k)|<\left|x_{L}(k)\right|$ なら, フィルタ係数の更新 はせず, step 5 へ。

step 2：あらかじめ与えた正の定数 $\alpha_{20}$ を使い, 式 (32)，（33）を計算する.

$$
\begin{aligned}
& C_{2}^{i}(k)=C_{2}^{i}(k-1)-\alpha_{20} z(k-i) e(k) \\
& (i=0, \cdots, N 2-1) \\
& z(k)=\sum_{i=0}^{M-1} E^{\imath} x(k-i)
\end{aligned}
$$

step $3: F(k)$ を計算する.

$$
\begin{aligned}
& F(k)=\left|C_{2}^{0}(k)\right|+\left|C_{2}^{1}(k)\right|+\cdots \\
& \quad+\left|C_{2}^{N 2-1}(k)\right| \cdots \cdots \cdots \cdots \cdots \cdots
\end{aligned}
$$

step $4: F(k)<1 / D$ なら, step 2 で求めたフィル夕 係数を用い, アルゴリズムを終了する.

$F(k) \geqq 1 / D$ なら, step 2 で求めたフィル夕係数を以 下のように修正する。

$$
\begin{aligned}
& C_{2}^{2}(k)=C_{2}^{2}(k-1)-\beta(k) z(k-i) e(k) \\
& (i=0, \cdots, N 2-1) \\
& \beta(k)=k_{1} \frac{1 / D-F(k-1)}{\sum_{i=0}^{N 2-1}|z(k-i) e(k)|}
\end{aligned}
$$

ただし， $k_{1}$ は， $0<k_{1}<1$ を満たす定数とし， $F(k-1)$ $<1 / D$ より $\beta(k)>0$ である.

step 5 : 得られたフィルタ係数を用い, 制御信号 $u(k)$ を計算し, step 1 へもどる.

ここで, $\beta(k)$ は, $C_{2}\left(z^{-1}, k\right)$ が $D F(k)<1$ を満足す るよう, 以下のように定めた。

まず, 式 (35) を用いたときの $F(k)$ は次式で計算さ れる。 


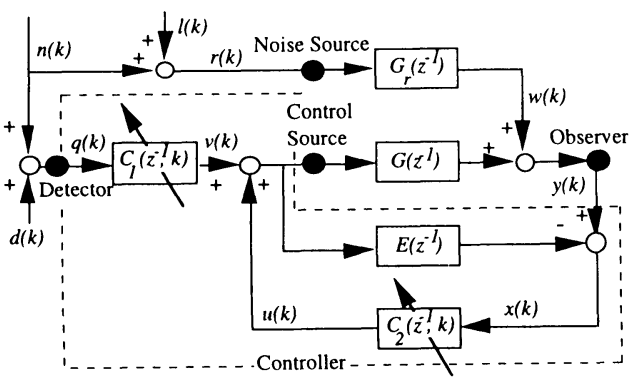

Fig. 4 2DF adaptive noise control system block diagram

$$
\begin{aligned}
F & (k)=\left|C_{2}^{0}(k)\right|+\left|C_{2}^{1}(k)\right|+\cdots+\left|C_{2}^{N 2-1}(k)\right| \\
& =\left|C_{2}^{0}(k-1)-\beta(k) z(k) e(k)\right|+\cdots \\
& +\left|C_{2}^{N 2-1}(k-1)-\beta(k) z(k-N 2+1) e(k)\right| \\
& \leq\left|C_{2}^{0}(k-1)\right|+\cdots+\left|C_{2}^{N 2-1}(k-1)\right| \\
& +|\beta(k) z(k) e(k)|+\cdots \\
& +|\beta(k) z(k-N 2+1) e(k)| \\
& =F(k-1)+\beta(k)(|z(k) e(k)|+\cdots \\
& +|z(k-N 2+1) e(k)|) \cdots \cdots \cdots \cdots \cdots \cdots \cdots \cdots
\end{aligned}
$$

ここで $F(k)$ が $D F(k)<1$ を満たすには, $\beta(k)$ が次式 を満たせばよいことは, 式(37)より明らかである。

$$
\begin{gathered}
F(k-1)+\beta(k)(|z(k) e(k)|+\cdots \\
\quad+|z(k-N 2+1) e(k)|)<1 / D
\end{gathered}
$$

ゆえに，式(38)より $\beta(k)$ は，式(36)として求められ る.

また, $D$ は, $G\left(z^{-1}\right)$ と $E\left(z^{-1}\right)$ との周波数特性を FFT により求めた後, $D \geq\left|\Delta\left(z^{-1}\right)\right|$ として求めること ができる.

以上により，ロバストな適応 FB 制御系を構成でき る.

$2 \cdot 2$ 二自由度制御系の設計方法 次に, $2 \cdot 1$ 節で 構成した FB 制御系に従来の FF 形適応フィルタを結 合した $2 \mathrm{DF}$ 制御系の構成を行う。その $2 \mathrm{DF}$ 制御系 のブロック図を図 4 に示す.

$2 \mathrm{DF}$ 制御系は, FF 補償器と FB 補償器とはおのお の独立に設計することができる，ここでは，FF 補償 器のフィルタ係数を filtered-X LMS アルゴリズムで, $\mathrm{FB}$ 補償器のフィルタ係数は RFXアルゴリズムを用 いて調整した。

\section{3. 実験方法ならびに結果}

$3 \cdot 1$ 実験方法 排気量 $2 l$ のセダン型乗用車の 車室内に騒音測定用マイク，騒音源用スピーカと制御 音源用スピーカを図 5 に示すように配置する。

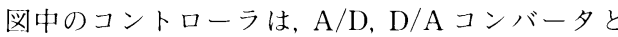

Table 1 Experimetal apparatuses

\begin{tabular}{l|l}
\hline \hline \multicolumn{1}{c|}{ Apparatuses } & \multicolumn{1}{|c}{ Type } \\
\hline Controller (DSP) & TI C30 \\
Microphone & ACO JAPAN 1/2 inch \\
Amplifier of microphone & ACO JAPAN Type 6044S \\
Speaker & BOSE 101RD \\
Amplifier of speaker & PIONEER SM-1800II \\
Filter & ROCKLAND MODEL852 \\
FFT ANALYZER & ONOSOKKI CF-360 \\
\hline
\end{tabular}

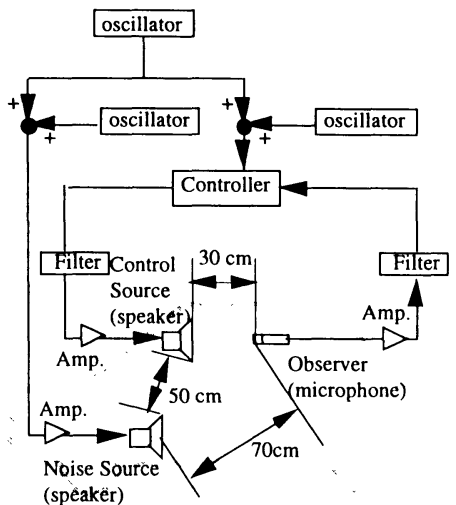

Fig. 5 Schematic diagram of the experimental condition

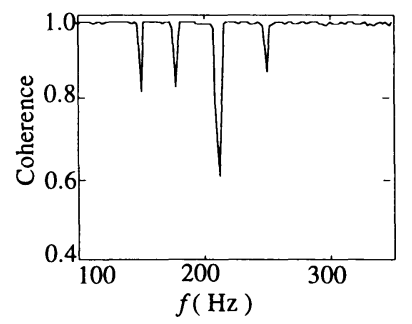

Fig. 6 Coherence between reference signal and noise

$\operatorname{DSP}($ 制御周期：1 ms) で構成され, マイクとコントロ ーラ間抢よび, コントローラ制御音源用スピーカ間に は信号の高周波成分を除くためにカットオフ周波数 $500 \mathrm{~Hz}$ のローパスフィルタを設けてある。実験機器 の一覧を表 1 に示す.

ノイズ用スピーカに付与されるノイズ信号は，ラン ダム信号と 4 種類のサイン信号を重ねて作られてお り，騒音のリファレンス信号は前記のランダム信号に ランダムな観測雑音を付加している.ノイズ信号とリ ファレンス信号とのコヒーレンスを図 6 に示す。

$3 \cdot 2$ 実験結果 制御スピーカと測定用マイク間 

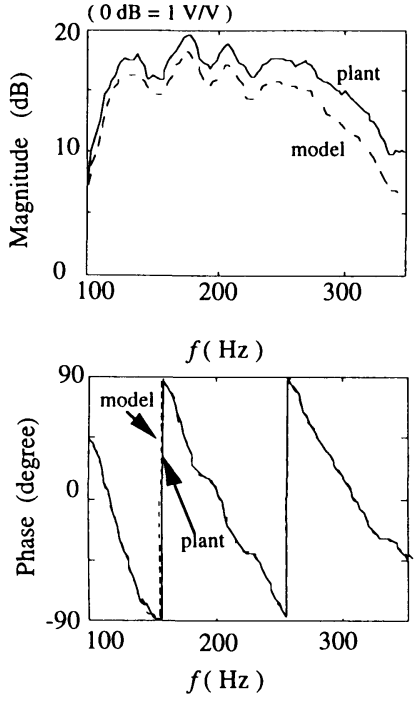

Fig. 7 Comparision between the plant and model

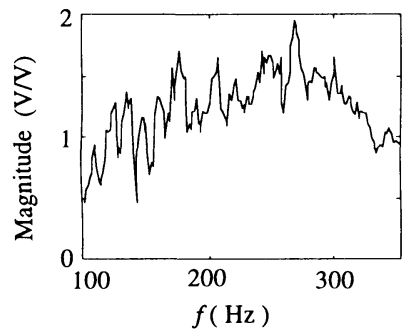

Fig. 8 Modeling error between the plant and model

の特性 $G\left(z^{-1}\right)$ とその同定モデル $E\left(z^{-1}\right)$ (タップ数 $M$ $=48)$ ，図 7 に示す。実験装置に RFX アルゴリズム を適用するためには， $G\left(z^{-1}\right)$ と $E\left(z^{-1}\right)$ の誤差 $\Delta\left(z^{-1}\right)$ の上限 $D$ を前もつて決める必要がある。図 8 に $\Delta\left(z^{-1}\right)$ のゲイン特性を示す。図 8 より, $\left|\Delta\left(z^{-1}\right)\right|$ の最 大值が 1.943(267.5 Hz)であることがわかる.ここで は, $G\left(z^{-1}\right)$ の変動は考慮せず, $G\left(z^{-1}\right)$ と $E\left(z^{-1}\right)$ との モデル化誤差のみを考慮し， $D=2$ と設定する.

図 5 の実験装置に, filtered X LMSアルゴリズム を用いた FF 補償器(タップ数 $N 1=32$ )を用いた結果 を図 9 に, RFX アルゴリズムを用いた $\mathrm{FB}$ 補償器 (夕 ップ数 $N 2=64)$ を用いた結果を図 10 に示す。次に, filtered-X LMSアルゴリズムを用いた FF 補償器と RFX アルゴリズムと組合せた $2 \mathrm{DF}$ 制御系を用いた 結果を図 11 に示す.

これらの図より，以下のことがわかる。（1）FF 補 償器は,コヒーレンスが良好な周波数帯域(図 6)で, 約 $10 \mathrm{~dB}$ 音圧が低減しているが, コヒーレンスの悪い

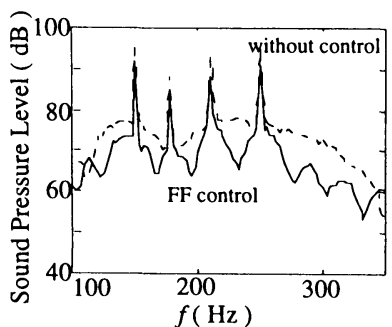

Fig. 9 Sound pressure level of error signal with or without FF compensator

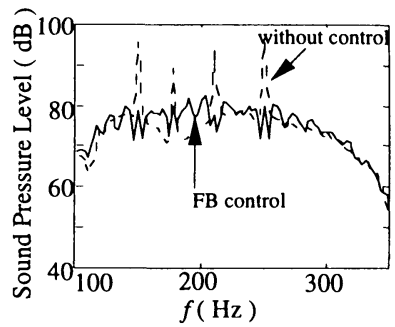

Fig. 10 Sound pressure level of error signal with or without $\mathrm{FB}$ compensator

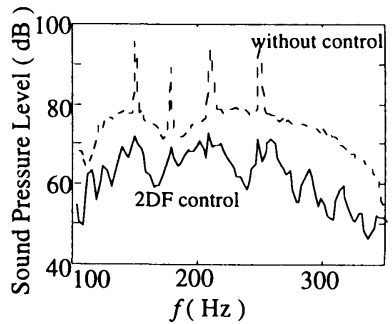

Fig. 11 Sound pressure level of error signal with or without 2DF compensator

周波数点およびそれに近接する周波数ではほとんど音 圧を低隇していない。（2 ）RFXアルゴリズムを用い た $\mathrm{FB}$ 補償器は, 周期性のある騒音を約 $20 \mathrm{~dB}$ 低減し ているが, 周期性のない騒音を低減していない。（3） $2 \mathrm{DF}$ 制御系は, 周期性の有無, コヒーレンスの良否に 関係なく騒音を $10 \mathrm{~dB}$ 以上低減している。

\section{4. ま と め}

本論文の内容を以下にまとめる.

（1）閉ループのロバスト安定性を補償する RFX アルゴリズムを提案した。このアルゴリズムは周期性 のある騒音を低減できる.

（2） RFXアルゴリズムを利用した FB 補償器を もつ $2 \mathrm{DF}$ 制御系を提案した。この方法は，騷音との 
コヒーレンスが良好なリファレンス信号がとれる騒音 だけではなく，周期性の騒音も低減できる。

（3）実験より, RFX アルゴリズムと RFX アルゴ リズムを利用した FB 補償器をもつ $2 \mathrm{DF}$ 制御系の有 用性を確認した。

\section{文献}

(1) Widrow, B. and Glover, J., Adaptive Noise Canceling: Principles and Applications, Proc. IEEE, 63-12 (1975) $1692-1716$

（2）浜田晴夫, 騒音・音場制御の現状と制御理論, 計測と制御, 324 (1992), 318-325.

(3) Erikson, L. J., Development of the Filtered U Algorith$\mathrm{m}$ for Active Noise Control, J. Acoust. Soc. Am, 89-1 (1991), 257-265.

(4) Eriksson, L. J., Active Sound and Vibration Control Using Adaptive Digital Signal Precessing, IEEE Proc ICASSP, (1993), 5154
（5）中路義晴・木下明夫, 車室内音場特性に着目したこもり 音のアクティブ制御技術の研究, 機論, 59-565, C (1993) 134-140.

( 6 ) Hong, W. H. W., Eghtesadi, Kh. and Leventhall, H. G., The tight-coupled monopole (TCM) and tight-coupled tandem (TCT) attenuators: Theoretical aspects and experimental attenuation in an air duct, J. Acoust. Soc. Am, 89-1 (1991), 257-265.

( 7 ) Munjal, M. L. and Eriksson, L. J., An analytical, onedimensional, standing wave model of linear active noise control system in duct, J. Acoust. Soc. Am, 84-3 (1988), 1086-1093.

(8) Nelson, P. A. and Elliot, S. J., Active Control of Sound, (1991), 204-230, Academic Press, London, U. K.

（9）尾川茂・神本一朗，自動車による空力騒音の予測と対策， 騒音と制御, 18-1 (1994) , 14-18.

(10) Widrow, B. and Strearns, S. D., Adaptive Signal Processing, (1985), 288-294, Printice-Hall, Englewood Cliffs. 